\title{
Etanercept efficacy in the treatment of chronic isolated inflammatory coxitis
}

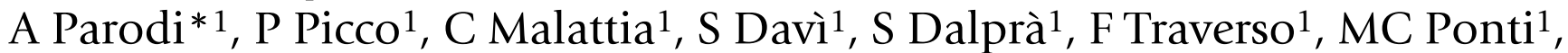 \\ A Buoncompagni ${ }^{1}$, A Loy ${ }^{1}$, S Viola ${ }^{1}$ and A Martini ${ }^{2}$
}

Address: ${ }^{1}$ Istituto G. Gaslini, Genova, Italy and ${ }^{2}$ Istituto G. Gaslini and Università di Genova, Genova, Italy

* Corresponding author

from $15^{\text {th }}$ Paediatric Rheumatology European Society (PreS) Congress

London, UK. 14-17 September 2008

Published: 15 September 2008

Pediatric Rheumatology 2008, 6(Suppl I):PI30 doi:I0.II86/I546-0096-6-SI-PI30

This abstract is available from: http://www.ped-rheum.com/content/6/SI/PI30

(c) 2008 Parodi et al; licensee BioMed Central Ltd.

\section{Background}

Chronic isolated inflammatory coxitis (CIIC) is characterized by exclusive involvement of coxo-femoral joints and an aggressive course leading to permanent structural damage, often requiring surgical treatment. Early commencement of disease-modifying or corticosteroid therapy has been suggested. To date, treatment with biological agents has not been reported. We describe the favourable response to etanercept in two girls with CIIC.

\section{Patients}

Patient 1 (15 years) and patient 2 (17 years) presented with a history of hip pain and limp lasting 3 and 5 years, respectively. Previous disease-modifying therapy was uneffective. Hip radiograph showed bilateral joint space narrowing in both patients and ankylosis of right hip in patient 2. ANA and HLA-B27 were negative in both cases. Active phase reactants were mildly increased in patient 2 . Magnetic resonance imaging (MRI) was obtained immediately before and after treatment with etanercept.

\section{Results}

Treatment with etanercept was followed by a significant improvement of pain and limitation of motion in patient 1: MRI after 6 months showed considerable reduction of synovial effusion. Synovitis and bone marrow oedema of femoral head, previously visualized, were not detectable.

Mild clinical improvement and normalization of inflammatory parameters were observed in patient 2: MRI after
12 months showed no progression of structural damage. MRI findings of disease activity were not detectable.

\section{Conclusion}

Etanercept treatment was effective in our patients. Clinical and radiological improvement was more evident in the patient with a shorter disease duration. Early treatment with anti-TNF agents should be considered in patients with CIIC to prevent severe structural damage. 